\title{
Block Collapse Risk Management
}

\author{
Kamchibek Kozhogulov, Olga Nikolskaya, \\ Institute of Geomechanics and Subsoil Development, National Academy of Sciences, Bishkek, Kyrgyz Republic \\ doi: https://doi.org/10.21467/abstracts.93.15
}

\begin{abstract}
ABST RA CT
The territory of Kyrgyzstan belongs to the tectonically active region. A characteristic feature of the rock massif is a block structure. The exploited gold ore deposits of Kyrgyzstan are upland, located in the zone of influence of discontinuous tectonic disturbances. In recent years, unplanned rockfalls have become more frequent at mining enterprises in Kyrgyzstan. Until now, due attention has not been paid to ensuring the safety of mining operations at such deposits. The stability assessment for such arrays is carried out according to existing methods acceptable for isotropic media. A block array is not. A distinctive feature of upland mineral deposits is that the sizes of the blocks in the weathering zone have different parameters and insignificant adhesion, and the blocks are kept in equilibrium only due to the action of gravity.

Therefore, the assessment of the influence of the block structure of the rock mass on the development of geomechanical processes is a new approach to solving the problems of ensuring the safety of mining and reducing risks in the development of upland deposits in zones of influence of tectonic disturbances. However, up to now, due attention has not been paid to issues of influence on development and risk management in the development of upland deposits in the mountain-folded areas, to which Kyrgyzstan belongs.
\end{abstract}

Minimization of the reasons that lead to unplanned caving in the upland quarries occurs during the risk management process. Modern risk management methods should be based on a strategy to prevent such collapses. To reduce risks, it is necessary to take into account that during mining operations the deformation and strength parameters of rocks change, vertical and horizontal stresses increase with depth, the stress concentration zone on the side of the open pit circuit increases, and the medium becomes block. The geological environment of a block structure, undergoing anthropogenic impact, changes its state: fracture from explosions is superimposed on the formed blockiness of the massif, the properties of the rocks and massif change, i.e. the geomechanical environment is changing.

Given these factors, it is necessary to assess the possible risks of collapse of the rocks of the instrument array, their volume and develop measures to reduce the risks of sudden collapse. Such measures include identification of discontinuous and plicative, tectonic disturbances, assessment of the natural stress state of the rock mass, determination of the physic-mechanical properties of the host rocks and ore, the presence and level of groundwater. In this case, it is necessary to identify the dominant factor and quantitatively assess the degree of its influence on the development of the process of stability violation and possible collapse.

For the instrument array of the block structure, risk management is reduced to evaluating the properties of the inter-block space filler and the ratio of the parameters of the blocks to the height of both a single ledge and the side of the quarry as a whole. The figure shows the change in adhesion in the dash array of the open pit, depending on the ratio of the pit side height $h$ to the linear dimensions of the elementary block 1 . The values of adhesion obtained on the samples are recalculated for adhesion in the array taking into account structural attenuation.

(C) 2020 Copyright held by the author(s). Published by AIJR Publisher in "Abstracts of The Second Eurasian RISK-2020 Conference and Symposium" April 12- 19, 2020, Tbilisi, Georgia. Jointly organized by AMIR Technical Services LLC, Georgian Technical University, Institute of Geography (Kazakhstan) and Russian Institute of Petroleum Geology and Geophysics.

DOI: $10.21467 /$ abstracts. 93 
The Second Eurasian RISK-2020 Conference and Symposium

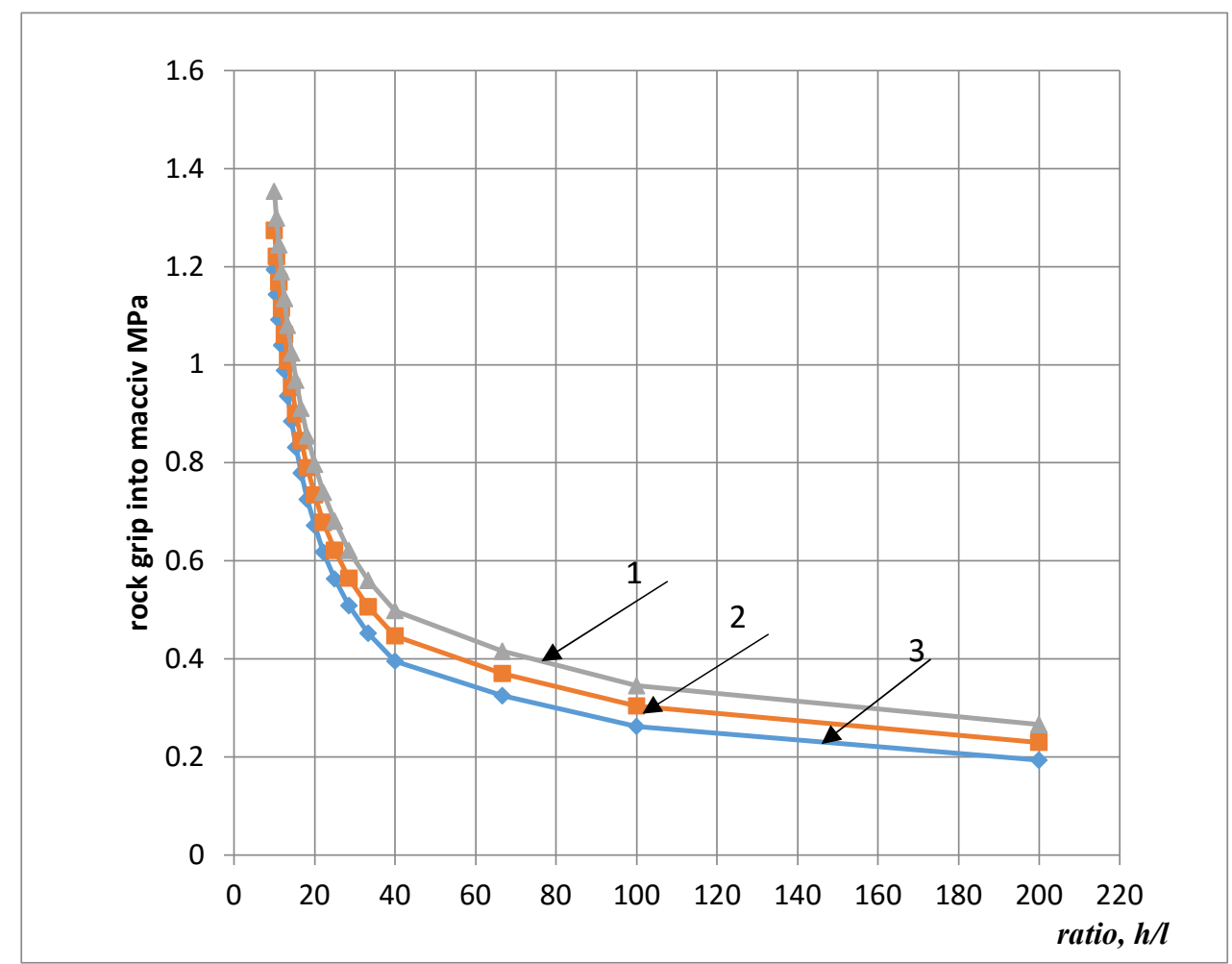

1-in the specimen $\mathrm{C}=6 \mathrm{MPa}$

2-rock grip in the specimen $\mathrm{C}=5,12 \mathrm{MPa}$

3-rock grip in the specimen $\mathrm{C}=4 \mathrm{MPa}$

Figure. Change in adhesion in the dash array of the open pit, depending on the ratio of the pit side height $\mathrm{h}$ to the linear dimensions of the elementary block 1 .

An equally important factor in managing the risks of collapse during the development of deposits by an upland quarry in a block massif is the parameters of drilling and blasting operations and the speed of movement of the face. In the off-site massif of the upland quarry during blasting operations, it is necessary to carry out blasting with preliminary slitting. In order to reduce the seismic effect on the array, the deceleration interval should be assigned in a series of charges for preliminary gap formation. 